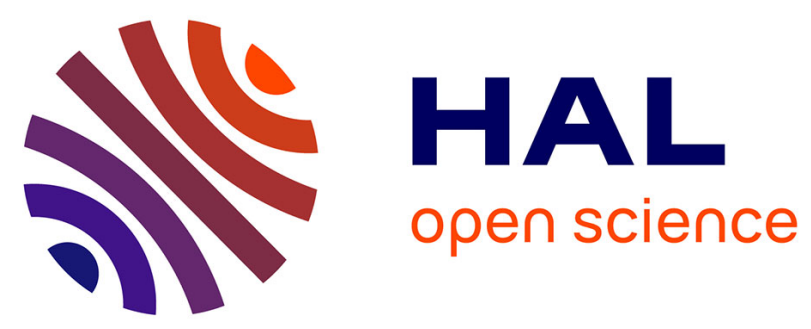

\title{
Trouver des partenaires et des financements
}

\author{
Justine Ancelin
}

\section{To cite this version:}

Justine Ancelin. Trouver des partenaires et des financements. Médiatiser la science en bibliothèque, 35, Presses universitaires de l'Enssib, 2016, Boîte à Outils, 979-10-91281-62-1. hal-01274019

\section{HAL Id: hal-01274019 \\ https://hal.science/hal-01274019}

Submitted on 15 Feb 2016

HAL is a multi-disciplinary open access archive for the deposit and dissemination of scientific research documents, whether they are published or not. The documents may come from teaching and research institutions in France or abroad, or from public or private research centers.
L'archive ouverte pluridisciplinaire HAL, est destinée au dépôt et à la diffusion de documents scientifiques de niveau recherche, publiés ou non, émanant des établissements d'enseignement et de recherche français ou étrangers, des laboratoires publics ou privés.

\section{(이) $\$$}

Distributed under a Creative Commons Attribution - NonCommercial - NoDerivatives| 4.0 


\title{
Trouver des partenaires et des finan- cements
}

\author{
Par Justine Ancelin
}

\section{S'intégrer au réseau des acteurs de la culture scientifique, tech- nique et industrielle}

Les bibliothèques sont rarement associées aux sciences, surtout en lecture publique. En réaction à ce manque de légitimité supposé, elles gagnent donc à s'associer à d'autres partenaires.

Le réseau des acteurs de la CSTI connaît depuis quelques années un mouvement général de restructuration, et est aujourd'hui mieux défini que jamais. Depuis la loi ESR du 22 juillet 2013, on assiste à une redéfinition des synergies au niveau territorial, et notamment régional, grâce au nouveau maillage offert par les Pôles Territoriaux de Référence (PTR) en charge de la coordination de la CSTI au niveau local. Ces PTR, dont la fonction est assumée le plus souvent soit par un CCSTI seul, soit par un consortium de divers acteurs dont des universités (Alsace, Bretagne, Lorraine, Pays-de-la-Loire etc.) et des bibliothèques publiques (Provence-Alpes-Côted'Azur), sont les interlocuteurs privilégiés des établissements qui souhaiteraient s'impliquer davantage dans la transmission des sciences, en accord avec leurs tutelles. C'est à cet échelon régional que doivent s'exprimer l'ensemble des acteurs de la CSTI, afin si besoin de faire remonter des propositions au Conseil national de la CSTI, par l'intermédiaire de son Comité opérationnel.

\section{Comprendre le financement de la culture scientifique}

Depuis début 2015, le CNL n'octroie plus de subventions aux bibliothèques pour des enrichissements de fonds thématiques. Les sciences n'étaient d'ailleurs que très peu concernées par ce type de demandes ${ }^{1}$. Dans le domaine des bibliothèques comme dans tant d'autres, c'est désormais souvent à l'échelle locale que se joue la partie, et celle-ci peut parfois inclure une dimension de culture scientifique. C'est par exemple le cas du contrat territoire-lecture en Essonne, dans le cadre duquel a été organisée en avril 2015 une journée professionnelle sur la vulgarisation scientifique ${ }^{2}$; ou de l'opération La Science se livre menée depuis plusieurs années par le Conseil général des Hauts-de-Seine ${ }^{3}$.

Mais ces opérations sont encore peu répandues, et on gagnera à solliciter également des institutions en rapport avec la culture scientifique au sens large, plutôt que liées au monde des bibliothèques.

\footnotetext{
${ }^{1}$ La commission Littérature scientifique du CNL continue toutefois à soutenir financièrement l'édition scientifique. C'est également le cas du SNE, qui se focalise sur l'édition de vulgarisation, l'édition scientifique spécialisée relevant de la commission universitaire pluridisciplinaire. Le SNE, associé à I'AMCSTI et soutenu par la SOFIA, organise également une opération de mise à disposition d'ouvrages de vulgarisation via des Kiosques (voir plus haut dans cet ouvrage l'entretien avec Catherine Allais et Sophie Bancquart), qui seront davantage proposés aux bibliothèques à l'avenir.

http://partageonslessciences.com/journee-pro-la-vulgarisation-scientifique-dans-les-livres-documentaires/ (consulté le 20 avril 2015).

3 http://applis.hauts-de-seine.net/Iss/2015/ (consulté le 20 avril 2015). L'opération a également essaimé en PoitouCharentes, sous la férule de l’Espace Pierre Mendès-France (CCSTI).
} 


\section{Les subventions ministérielles et interministérielles}

La CSTI bénéficie d'environ 200 millions d'euros ${ }^{4}$, principalement gérés par la Mission interministérielle Recherche et enseignement supérieur (MIRES). Cette mission recouvre dix programmes, dont plusieurs intéressent la CSTI :

- Le programme 172 Recherches scientifiques et technologiques pluridisciplinaires consacre 2,54 M€ au renforcement des liens entre science et société. Près d'un million est consacré aux actions de diffusion comme la Fête de la Science (appel à projets national annuel) et au soutien aux acteurs de la CST. Si les bibliothèques ne sont pas nommées, elles peuvent prétendre à ces crédits en proposant des actions de ce type, surtout en s'associant à des partenaires mieux reconnus comme des associations.

- Le programme 186 Recherche culturelle et culture scientifique consacre 8,79 M€ à la conservation/valorisation du patrimoine scientifique et à la création artistique en lien avec les sciences, qui ne concerne toutefois que peu de bibliothèques. 108,35 M€ réservés à « la promotion de la CSTI auprès du public le plus large possible ${ }^{5}$ » sont par ailleurs destinés à Universcience, pôle national de référence pour la CSTI. La mise en œuvre de partenariats est un objectif affirmé de cet axe ${ }^{6}$, et l'on gagnera à solliciter Universcience pour trouver des financements.

- Le programme 150 Formations supérieures et recherche universitaire finance musées scientifiques, musées d'histoire naturelle et OCIM, tous acteurs de la CSTI auxquels les bibliothèques s'associeront avec profit.

- Enfin, les acteurs régionaux comme les CCSTI percevront par le biais des DRRT7 3,6 M€ de budget de fonctionnement grâce au programme 119 (Concours financiers aux collectivités territoriales), ainsi que plusieurs dizaines de millions d'euros dans le cadre des contrats de plan État-régions pour la période 2015-20208. La DRRT et la région PACA élaborent ainsi chaque année des appels à projets pour les manifestations de culture scientifique ${ }^{9}$.

\section{Le Programme d'Investissements d'Avenir (PIA1)}

L'action Développement de la CSTI était incluse dans l'action-programme 324 Internats d'excellence et égalité des chances du PIA1, mise en œuvre par l'appel permanent à projets Égalité des chances et promotion de la culture scientifique piloté par l'Agence nationale pour la rénovation urbaine. 46 projets se sont partagé une dotation globale de $100 \mathrm{M} €$. Aucune bibliothèque n'est explicitement mentionnée comme porteur de projet ${ }^{10}$, ce qui ce comprend compte-tenu du budget minimum à prévoir pour une telle entreprise (250 000€). Mais certains projets n'ont pas encore réellement démarré, ce qui permet aux bibliothèques de s'associer encore aux universités ou collectivités territoriales, pour peu que leurs objectifs concordent.

Parmi les projets sélectionnés, on compte notamment ESTIM (Égalité d'accès aux sciences et techniques, à l'innovation et au multimédia), porté par Universcience. Il se propose de fédérer les acteurs de la CSTI par le biais de nouveaux outils et services permettant de « coproduire et mutualiser des ressources et des outils de médiation scientifique », et d'attribuer des bourses de contenus pour des projets liés au numérique. Les bibliothécaires intéressés par ces nouvelles ressources, et dont la connaissance des problématiques en rapport avec le numérique serait un

\footnotetext{
${ }_{5}^{4}$ MESR, Projet de loi de finances 2015 [en ligne] <http://www.senat.fr/rap/a14-112-5/a14-112-520.html>

${ }_{5}$ MCC, Projet de loi de finances 2015 [en ligne] < http://www.culturecommunication.gouv.fr/Projet-de-loi-de-finances2015> (consulté le 4 avril 2015)

PLF 2015 - Extrait du bleu budgétaire de la mission: Recherche et enseignement supérieur [en ligne] < http://www.performance-

publique.budget.gouv.fr/sites/performance publique/files/farandole/ressources/2015/pap/pdf/DBGPGMPGM186.pdf> (consulté le 4 avril 2015)

7 Depuis la loi du 22 juillet 2013. Auparavant, c'était Universcience qui était chargé de ventiler ces crédits.

8 Au moment où paraît cet ouvrage, le montant des crédits dédiés à la CSTI dans les prochains CPER n'est pas encore connu. II était de 27,955 M€ pour la période 2007-2014.

${ }_{9}$ Voir en ligne http://www.culture-science-paca.org/node/1357 (consulté le 10 avril 2015) 2015)

${ }^{10}$ Voir en ligne http://www.anru.fr/index.php/fre/Programmes/Investissements-d-avenir/Jeunesse (consulté le 29 avril
} 
atout, s'intéresseraient avec profit à ce projet, par exemple en participant à son portail numérique ${ }^{11}$.

D'autres projets d'envergure régionale, comme PicardieScience ${ }^{12}$ ou CERCo en Lorraine, visent à fédérer l'ensemble des acteurs de la CSTI sur ces territoires : c'est dans ce genre de cadre que gagneraient à s'intégrer les bibliothèques de taille modeste, notamment en lecture publique.

\section{Les autres appels à projets}

A l'échelle européenne, le programme de recherche et d'innovation Horizon 2020 inclut un programme Science avec et pour la Société. Toutes les propositions visant à rendre les carrières scientifiques plus attractives, à favoriser l'égalité des sexes, l'enseignement des sciences et l'accessibilité et l'utilisation des résultats de la recherche entrent dans son périmètre, et offrent aux bibliothèques, universitaires notamment, des pistes pour monter des projets et recueillir des subventions. Le point de contact français pour ce programme est l'AMCSTI.

Quant à l'ANR, elle envisage les actions de CSTI comme la sous-partie d'une réponse ambitieuse à un appel à projets plus généraliste ${ }^{13}$. S'il semble inconcevable qu'une bibliothèque réponde seule à un appel de ce type, une collaboration avec d'autres partenaires du monde de la recherche, par exemple dans le cadre d'une COMUE, semble réaliste.

Si le réseau des acteurs de la CSTI commence à se structurer de manière claire, l'organisation des moyens publics consentis au partage de la CSTI est encore floue. Mais qui mieux qu'un bibliothécaire sait organiser sa veille et trier l'information?

${ }_{12}^{11}$ http://www.estim-science.fr/ (consulté le 29 avril 2015) Note de Synthèse du projet [en ligne] <
recherche.gouv.fr/file/D.R.R.T. Picardie/63/4/Synthese PicardieScience 2.0 340634.pdf $>$ (consulté le 4 avril 2015)

${ }^{13}$ Voir en ligne <http://www.agence-nationale-recherche.fr/Diffusion> (consulté le 4 avril 2015) 
9488 signes au lieu de 7200 (4 pages) 